\title{
MANAGING CROSS-CULTURAL ONLINE COMMUNICATION IN MULTICULTURAL PROJECT TEAMS: THE CASE OF CULTOUR+ PROJECT
}

\author{
Luis Ochoa Siguencia \\ The Jerzy Kukuczka Academy of Physical Education in Katowice, Poland \\ Martín Gómez-Ullate García de León \\ University of Extremadura, Spain \\ Renata Ochoa-Daderska \\ Research and Innovation in Education Institute, Poland
}

\begin{abstract}
The paper aims to present the process and partnership building in multicultural project teams through the use of information and communication technologies (ICT) taking into account the Cultour+ communication project management plan to build virtual teams. The research developed by Research and Innovation in Education Institute from Poland try to show the effective way of using ICT in project communication management by analyzing the way it fits in with various project activities. This approach may facilitate the choice of appropriate tools by other project team and be taken as a best practices on how ICT can support key processes like leadership, management, communication and co-operation within other European project teams.
\end{abstract}

Keywords: Communication, ICT, long-life learning, project management, Virtual meetings.

\section{Information and Communication Technology and project management}

Information and Communication Technology (ICT) has dramatically changed the business environment. Organization cultures and business strategies must keep updated their use of ICT in their organizations. It significantly affects strategic options and creates opportunities and issues that top and middle managers need to address in many aspects of their business activities (Bakia, et al., 2012; Mavroudi \& Hadzilacos, 2013).

ICT has clearly impact in the following aspects of our organization:

- Business strategy

- Organization Culture

- Organization Structures

- Management Processes

- Work

- The workplace 
Our paper make emphasis in Communication management, because this is one of the most important factors that determines the success of European projects managements when we have to deal with different partners from different cultures, languages, professional fields and business cultures. Our and others experiences show that organizations that have developed effective ways to manage communications in the project end more projects in the assumed time and budget, compared to organizations that communicate inefficiently (Cieslikowski, 2015). This has a significant impact on the results of the entire project management (Walker, 2015) and affects quality of project outputs. Figure one shows which aspects must take into account our communication plan (see figure 1).

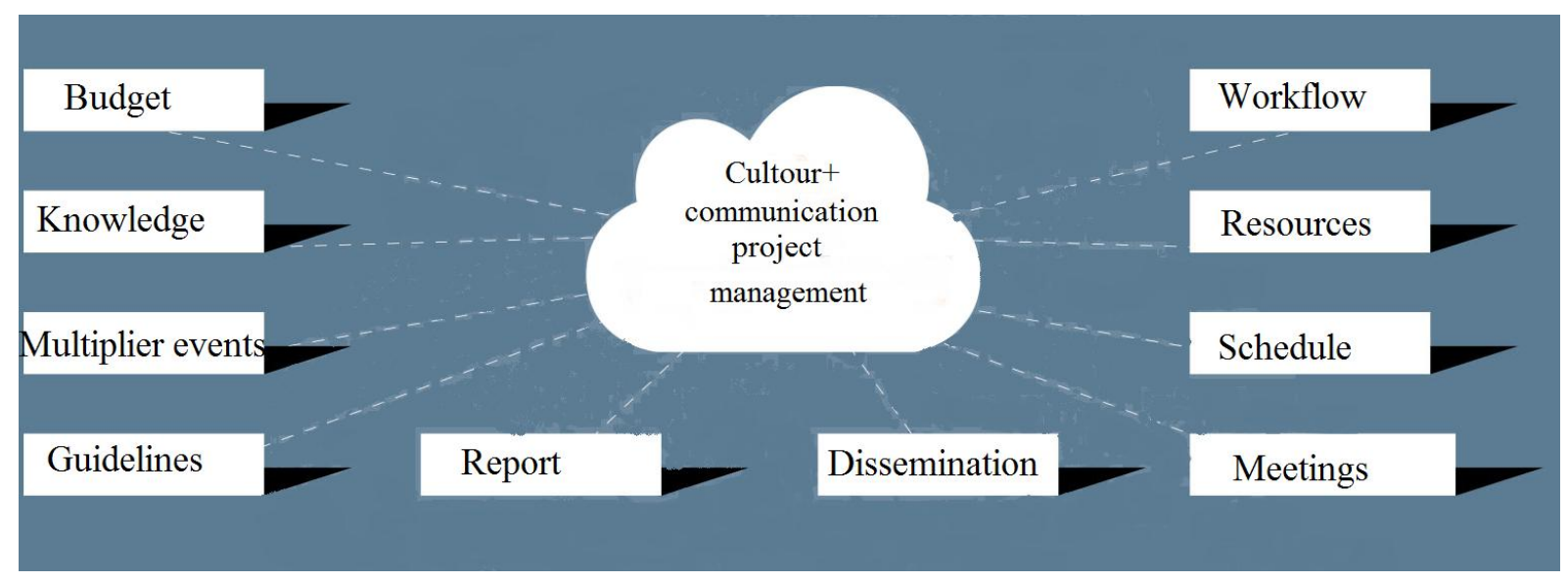

Figure 1 Communication project management

It is necessary to have in mind the objectives of the project during the whole projects' life to be able to maintain a communication plan active where all activities to be performed are covered but with not exaggerating the number of online meetings. Communication concerning the project should begin before the project start and end long after its formal closure. In fact, history and frequency of contacts affect directly the quality of the project. The processes of exchange of information should include not only members of the project team, but also all stakeholders and people in some way will have some impact, both prior to its implementation, during the implementation and after implementation.

The content of communication must be adjusted to the recipient. The technical team will be very good understanding of technical issues, while midlevel managers will be able to assimilate the general technical specifications, and the terminology will operate fluently if technical terminology is explained. An international cross-cultural project faces the challenge of getting agreement from people from very different cultural and professional backgrounds adapting the project's objectives to their own objectives and agenda. Although technical 
terminology and indicators help to standardize communication processes, they are far from being univocally understood. This is quite different from the senior managers who speak the language of business and need „hard data” and focused on business value, costs and profits. It is why a proper management of communication in the project requires organizations to take appropriate measures to ensure that the information provided will not be only a „data stream", but will add value to the project.

The value of a well communication plan is accurate understanding of each project stakeholders on what role they will have in the project, and why their involvement in the project is particularly important. Adjustment of the broadcast content to the recipient is one method, which allows to reach such a value.

A good way to manage communication in a project is to search for secondary data and best practices on communication management. Such practices are used more often in organizations that have high coefficients of performance, compared to those whose efficiency can be defined as average. Such practices may be used within organizational communication strategy where usually is specified what should be communicated, to whom, how often and in what form. It is important to clarify roles in communication, the person responsible for it, and explain why compliance with the communication strategy is important (see figure 2).

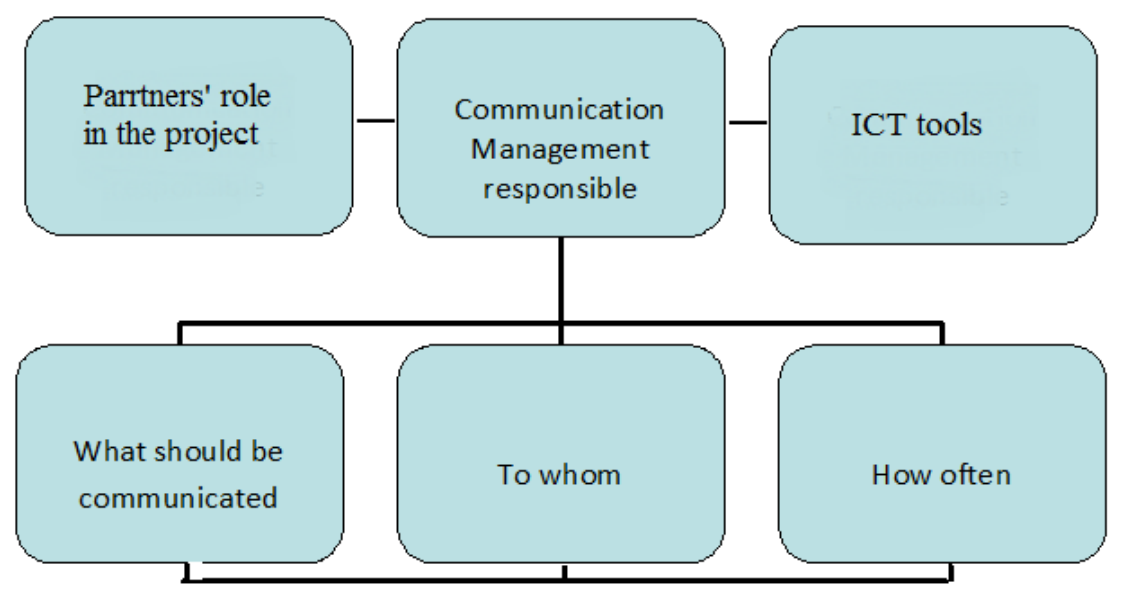

Figure 2 Communication strategy

Communication management in the project is the first step to save time [time management] and money [resource management] by the organization. There is also a complex task that requires taking into account the specific nature of the institutions involved and the coordinator [the person who leads] the project, the various groups of stakeholders, their needs and the situations in which they are located. In the light of the benefits it seems, however, that 
communication management in the project is an effort worth taking (Caganova, et al., 2015)

Good communication means:

- $\quad$ planning to determine who and what information needs to be prepared and who should be the recipient of this information. The plan also specifies the frequency of the preparation of the information, their distribution channels and methods of communication

- Distributing information properly means to develop mechanisms for project activities that will ensure that the information will be created and reached the appropriate users in the design process.

- Controlling should be periodically throughout the project life cycle. Speed of information on important matters and distribution of information to relevant stakeholders are the basic objectives of an efficient distribution system. The reporting system is the basis of proper communication in the project (Malina \& Selto 2001). When planning project activities, we are planning to essential reporting system and periodic reviews of project work

- Motivating is a good way to engage every member of the project team. Only after a good motivation, the partners will act through the tone and style of our communications

\section{Cultour+ project and communication management}

CULTOUR+ project is a Strategic Partnership (SP) of universities, local governments, SMEs and NGOs, that following the mainlines of the Higher Education Modernization Agenda, aims to offer high quality and innovative courses and tools, integrating innovation, international mobility and cross-border cooperation to enhance capacity building in higher education curricula in the fields of cultural tourism and hospitality, cultural management and shared cultural heritage.

A research done in January 2016 to local managers involved in Cultour+ project show that participants all of them are good skills in Information and Communication Technology management and that most of them has experience in virtual communication applications.

When asked which of the following e-tools are you familiar with and to which extent, we found that most of the local managers are aware of a good number of online tools that can help better manage internal and external communication (Gallaugher \& Ransbotham, 2010). We have analysed tools like:

- tools used for direct communication: email, online voice, text chat, Colibri 
- collaboration tools to share documents and work on them remotely: Pbworks, google drive

- $\quad$ social media tools for internal communications and announcements: Facebook

Taking into account the group answer we can conclude that the most confortable tool for internal and external communication is the e-mail, $89 \%$ can teach others to use it and $11 \%$ feel comfortable sinus it. The second group of tools are: Website, Chat, Instant messengers, where $56 \%$ feel comfortable using it and the rest even can teach others to use it. In third place we found Social networks and Pbworks, $44 \%$ of researched, feel comfortable to use it.

Concerning video conference tool, we decided to use colibri because $56 \%$ are able to use it, $22 \%$ feel comfortable and the other 22 are experts that can teach others to use it.

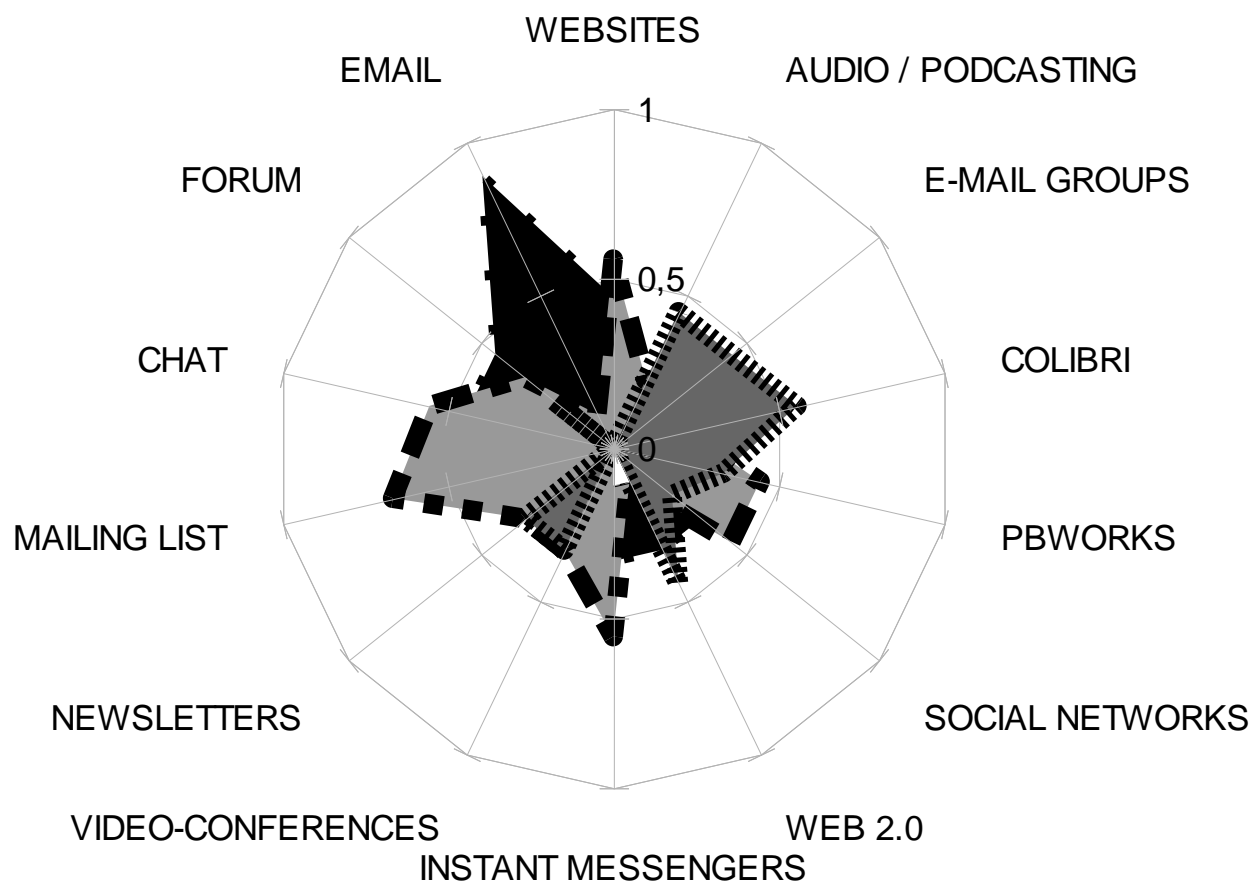

\footnotetext{
$\square$ I have heard of it but never used it

; I can manage, but some help would be useful

E I can use it. I feel comfortable using it

I can teach others to use it
}

Figure 3 Virtual Intercultural Team Tool: ICT competencies 
The Communication System and plan was set up, tested and agreed by all partners in the first month, although there have been advances in this in the preliminary phase as reserving a space in the UEX's Adobe Connect Platform or creating an eTwinning project via Radomska Higher School. Telephone and post communications were to be tested to prevent communication risks.

Internal communication follows a regular weekly virtual meeting base, continuous e-mailing and casual virtual on-line connections. Protocols are being designed for general communications and subprojects (Countries Business Projects) and sub-areas or teams (Communication System, Research, Project Management, Educational Programme, Dissemination Plan,...). These allow the core foundational team to grow in number with the adhesion of new network partner and significant stakeholders maintaining fluent and effective communications.

The system is flexible and incorporate feedback from users to improve quality and effectiveness (Vaishnavi \& Kuechler, 2015). We have foreseen also virtual conferences. They are scheduled taking into account the Project plan and the Risk management plan. The contract coordinator presented a preliminary proposal during the kick-off meeting and the dissemination and impact plan:

- Quantity and quality of promotional and dissemination material produced

- News in mass media

- CULTOUR+ Youtube channel (visits and „likes”)

- Impact of website (number of hits, unique visitors, length of stay, most popular pages, peaks, etc. through web statistic module)

- $\quad$ Links to CULTOUR+ website

- $\quad$ CULTOUR+ website visits (by country)

- Scientific publications (impact, downloads, cites)

- Attendants to multiplier events

- Number of established contacts with: Higher institutions, Government institution, ONGs, Experts, Educators

- Number of scientific papers published

- Number of workshops/conferences organized

- Number of dissemination activities in transnational and local conferences

All partners will participate via Internet to these local events. The communication System and actual internal communications is coordinated by the University of Extremadura through the Pbworks, Google drive and Colibri platform. External communications and dissemination plan coordination were planned to rotate every six months throughout the project duration (University of Extremadura, Research and Innovation in Education Institute, Varna Free 
University, Egina, Futuro Digitale and Radomska Wysza Szkola). The Research and Innovation in Education Institute from Poland (INBIE) designed a webpage for initial and exhaustive dissemination that is updated directly by all partners. This is possible because of the use of Pbworks platform where a simple password give access to all information.

There will be a monthly internal and external reports, online dissemination of all activities developed and implemented during the projects' life and the network.

Finally we plan numerous local public meetings and workshops for spreading information/results and measure the beneficiaries interest.

\section{Conclusion}

For a successfully communication management and project management, it is necessary that Cultour+ project should articulate formal actions such as:

- $\quad$ Set up communication system (protocols) (CST)

- Internal communication system through Pbworks, co-working spaces and Virtual conferences applications (such as Adobe Connect)

- External Communications System using Web page, Social networks, Youtube Channels, UE Spaces and Partner websites

- Educational Program Communications System (Percy, 2015; Sharp, 2015) using Moodle platform with virtual collaboration spaces, webinars and clips, observatories -statistical updated data-, coworking spaces, Virtual conferences application (such as Adobe Connect) and Open Education Europa Blogs, Groups and Moocs

But all these strategies and online instruments does not guarantee an internal fluid communication or an external quality dissemination. The most important is the motivation and collaboration of all partners. Complex intercultural, inter-professional and disciplinary contexts and backgrounds make communication a hard challenge to be overcome through motivation, creativity and innovation.

\section{Acknowledgments}

This paper was supported by the European project Cultour+ "Innovation and Capacity Building in Higher Education for Cultural Management, Hospitality and Sustainable Tourism in European Cultural Routes", and reflects the views only of the authors, and the European Commission cannot be held responsible for any use which may be made of the information contained therein. 
Luis Ochoa Siguencia, Martín Gómez-Ullate García De León, Renata Ochoa-Daderska. Managing Cross-Cultural Online Communication in Multicultural Project Teams...

\section{References}

Bakia, M., Shear, L., Toyama, Y., \& Lasseter, A. (2012). Understanding the Implications of Online Learning for Educational Productivity. Office of Educational Technology, US Department of Education.

Caganova, D., Cambal, M., \& Weidlichova Luptakova, S. (2015). Intercultural managementtrend of contemporary globalized world. Elektronika ir Elektrotechnika, 102(6), 51-54.

Cieslikowski, K., (2015). Business tourism management. Global and local aspects. AWF Katowice, Poland, 131 - 137

Gallaugher, J., \& Ransbotham, S. (2010). Social media and customer dialog management at Starbucks. MIS Quarterly Executive, 9(4), 197-212.

Malina, M. A., \& Selto, F. H. (2001). Communicating and controlling strategy: an empirical study of the effectiveness of the balanced scorecard. Journal of management accounting research, 13(1), 47-90.

Mavroudi, A., \& Hadzilacos, T. (2013). Learning needs analysis of collaborative e-classes in semi-formal settings: The REVIT example. The International Review of Research in Open and Distributed Learning, 14(5).

Percy, K. (2015). Adult access to learning. Handbook of Educational Ideas and Practices (Routledge Revivals), 296.

Sharp, C. (2015). Participative transformation learning and development in practising change. Action Learning: Research and Practice, 12(2), 250-254.

Vaishnavi, V. K., \& Kuechler, W. (2015). Design science research methods and patterns: innovating information and communication technology. CRC Press.

Walker, A. (2015). Project management in construction. John Wiley \& Sons. 